\title{
Baseline-Dependent Responses of Soil Organic Carbon Dynamics to Climate and Land Disturbances
}

\author{
Zhengxi Tan ${ }^{1}$ and Shuguang Liu ${ }^{2}$ \\ ${ }^{1}$ ARTS, US Geological Survey (USGS), Earth Resources Observation and Science (EROS) Center, 47914 252nd Street, Sioux Falls, SD \\ 57198, USA \\ ${ }^{2}$ US Geological Survey (USGS), Earth Resources Observation and Science (EROS) Center, Sioux Falls, SD 57198, USA
}

Correspondence should be addressed to Zhengxi Tan; ztan@usgs.gov

Received 21 November 2012; Revised 24 January 2013; Accepted 25 January 2013

Academic Editor: Alessandro Piccolo

Copyright (C) 2013 Z. Tan and S. Liu. This is an open access article distributed under the Creative Commons Attribution License, which permits unrestricted use, distribution, and reproduction in any medium, provided the original work is properly cited.

\begin{abstract}
Terrestrial carbon $(\mathrm{C})$ sequestration through optimizing land use and management is widely considered a realistic option to mitigate the global greenhouse effect. But how the responses of individual ecosystems to changes in land use and management are related to baseline soil organic C (SOC) levels still needs to be evaluated at various scales. In this study, we modeled SOC dynamics within both natural and managed ecosystems in North Dakota of the United States and found that the average SOC stock in the top 20 $\mathrm{cm}$ depth of soil lost at a rate of $450 \mathrm{~kg} \mathrm{Cha}^{-1} \mathrm{yr}^{-1}$ in cropland and $110 \mathrm{~kg} \mathrm{Cha}^{-1} \mathrm{yr}^{-1}$ in grassland between 1971 and 1998 . Since 1998, the study area had become a SOC sink at a rate of $44 \mathrm{~kg} \mathrm{Cha}^{-1} \mathrm{yr}^{-1}$. The annual rate of SOC change in all types of lands substantially depends on the magnitude of initial SOC contents, but such dependency varies more with climatic variables within natural ecosystems and with management practices within managed ecosystems. Additionally, soils with high baseline SOC stocks tend to be $\mathrm{C}$ sources following any land surface disturbances, whereas soils having low baseline $\mathrm{C}$ contents likely become $\mathrm{C}$ sinks following conservation management.
\end{abstract}

\section{Introduction}

Soil carbon (C) dynamics and change rate caused by land surface disturbances and climate change are generally related to the magnitude of initial soil organic C (SOC) [1-10]. These investigators observed a strong negative relationship between the rate of change in SOC and the baseline SOC content, and this relationship has been thought to have no effect on any other soil properties [4]. However, the effect of the baseline SOC content has been neither evaluated under considerations of individual land use and land cover (LULC) types and their temporal change nor counted in the assessment on the potential of terrestrial ecosystem $\mathrm{C}$ sequestration through adaptation strategies.

To further assess ecosystem-climate system feedback and define a strategy to reduce the buildup of atmospheric greenhouse gases using terrestrial $\mathrm{C}$ sequestration as an option, it is necessary to improve our understanding of not only the $\mathrm{C}$ biogeochemical cycles associated with LULC dynamics, but also the sensitivity of SOC stock to transient land disturbances and its relation to the baseline SOC level at multiple temporal and spatial scales. And the data obtained from specific sites have to be upscaled to a regional scope through modeling algorithms that can constrain uncertainties derived from local scales.

The General Ensemble biogeochemical Modeling System (GEMS) is a new type of multilevel simulation system designed to integrate dynamic LULC data into a modeling system over large areas [11]. For cropping ecosystems, GEMS can generate crop rotations/combinations based on agricultural census data and produce various soil input data for biogeochemical simulations. Because of its transient LULCoriented advantages over other existing modeling approaches and its successful application to diverse ecosystems $[6,8$, $9,12]$, GEMS was used in this study to assist in evaluating 
TABLE 1: Land use/cover types and areal percentages within the study area.

\begin{tabular}{|c|c|c|c|c|c|c|c|c|c|c|}
\hline Land use/cover type & 1998 & 1999 & 2000 & 2001 & 2002 & 2003 & 2004 & 2005 & 2006 & 2007 \\
\hline Water (\%) & 9.8 & 9.8 & 9.4 & 11.3 & 9.5 & 9.5 & 9.4 & 9.5 & 9.5 & 9.6 \\
\hline Urban (\%) & 4.4 & 4.4 & 4.4 & 4.0 & 4.1 & 4.2 & 4.3 & 4.1 & 5.0 & 5.6 \\
\hline Forests (\%) & 0.5 & 0.5 & 0.5 & 0.5 & 0.6 & 0.5 & 0.5 & 0.5 & 0.6 & 0.6 \\
\hline Grassland (\%) & 34.5 & 34.5 & 33.0 & 31.6 & 29.0 & 30.5 & 29.7 & 32.6 & 27.6 & 31.0 \\
\hline \multicolumn{11}{|l|}{ Agricultural lands (\%) } \\
\hline Pasture & 14.0 & 14.0 & 14.0 & 14.0 & 14.0 & 14.0 & 14.0 & 14.0 & 13.9 & 13.9 \\
\hline Barley & 4.3 & 4.3 & 1.6 & 3.7 & 0.5 & 2.2 & 1.3 & 1.0 & 0.6 & 0.1 \\
\hline Corn & 0.5 & 0.5 & 1.8 & 3.9 & 1.9 & 2.4 & 0.2 & 5.3 & 4.7 & 13.5 \\
\hline Soybeans & 1.0 & 1.0 & 4.7 & 5.0 & 11.6 & 21.3 & 17.7 & 14.5 & 19.9 & 14.6 \\
\hline Other crops & 4.5 & 4.5 & 5.0 & 4.7 & 4.5 & 5.5 & 2.1 & 2.1 & 1.8 & 0.3 \\
\hline Spring wheat & 8.2 & 8.2 & 12.6 & 6.8 & 15.0 & 3.8 & 7.2 & 6.1 & 5.6 & 3.6 \\
\hline Fallow & 3.4 & 3.4 & 2.5 & 5.9 & 2.0 & 1.9 & 9.3 & 3.0 & 4.3 & 0.1 \\
\hline Sunflowers & 10.7 & 10.7 & 6.3 & 4.3 & 3.1 & 0.0 & 0.1 & 3.0 & 1.7 & 0.9 \\
\hline Sum & 46.5 & 46.5 & 48.4 & 48.2 & 52.6 & 51.0 & 51.9 & 49.1 & 52.6 & 47.0 \\
\hline Wetlands (\%) & 4.3 & 4.3 & 4.3 & 4.3 & 4.3 & 4.3 & 4.3 & 4.3 & 4.8 & 6.2 \\
\hline Sum (\%) & 100 & 100 & 100 & 100 & 100 & 100 & 100 & 100 & 100 & 100 \\
\hline
\end{tabular}

The total land area is about $260 \mathrm{~km}^{2}$.

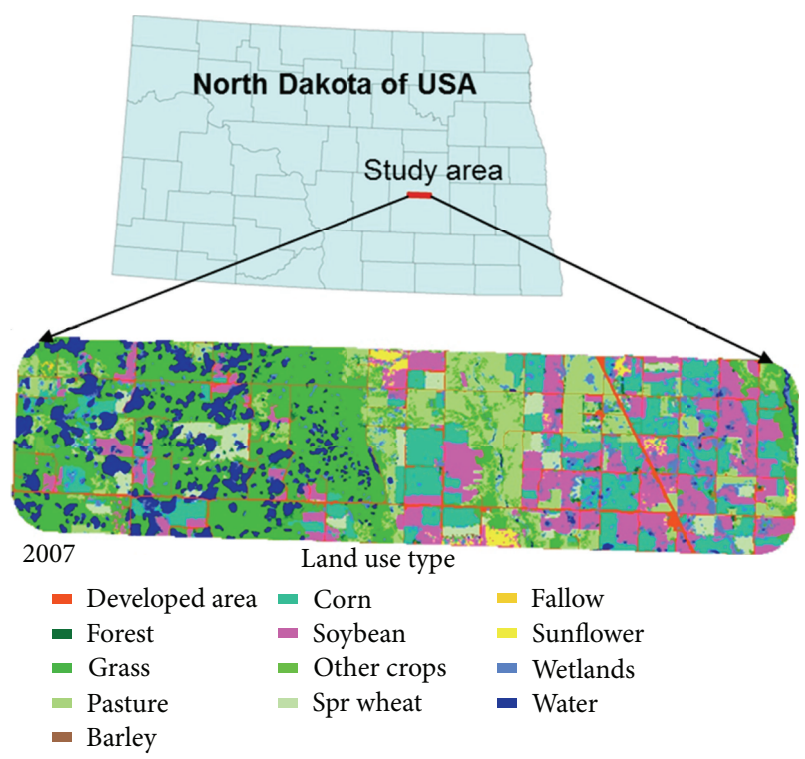

Figure 1: Location of the study area and the spatial distribution of its land cover types in 2007.

responses of soil carbon stock to climate and land disturbances in the US Prairie Pothole Region.

\section{Materials and Methods}

2.1. Study Area. The study area is located in north-central Stutsman County of North Dakota $\left(47^{\circ} 19^{\prime}-47^{\circ} 29^{\prime} \mathrm{N}\right.$ and $109^{\circ} 42^{\prime}-110^{\circ} 20^{\prime}$ W) (Figure 1) and covers an area of about $260 \mathrm{~km}^{2}$. This area is part of the US Prairie Pothole Region. Its semiarid climate had a mean annual precipitation of $399 \mathrm{~mm}$ and a mean annual temperature of $3.5( \pm 2.1)^{\circ} \mathrm{C}$ for the period from 1998 to 2007, when about 73\% of the annual precipitation occurred during the growing season from May to September. According to the US Department of Agriculture (USDA) Cropland Data Layer (see Section 2.3.1), the LULC consisted mainly of cropland and grassland, accounting for $81 \%$ in 1998 and $78 \%$ in 2007 (see Figure 1). Wetlands increased from $4.3 \%$ to $6.2 \%$. The annual variation in the area of either cropland or grassland was associated with the rotation between cropping systems and conversions between grassland and cropland caused by the implementation of conservation measures such as the Conservation Reserve Program and the Grasslands Reserve Program. Planted areas for barley, spring wheat, and sunflowers declined sharply from 1998 to 2007. Meanwhile, the areas for corn and soybean expanded from $0.5 \%$ to $13.5 \%$ and from $1.0 \%$ to $14.6 \%$, respectively (Table 1). A marked increase in wetland area since 2006 was due to implementing the Wetland Reserve Program [13]. These annual changes were one of the fundamental factors driving SOC dynamics.

\subsection{Model Simulations}

2.2.1. General Ensemble Biogeochemical Modeling System (GEMS). GEMS [14] has been used to assess the ecosystem C dynamics for diverse terrestrial ecosystems across the world. GEMS was developed for upscaling C stocks and fluxes from sites to regions with a spatially explicit [15] and dynamic consideration of LULC change [11]. GEMS relies on a sitescale biogeochemical model to simulate $\mathrm{C}$ dynamics at a site (e.g., EDCM-Erosion-Deposition-Carbon Model [16]). The spatial deployment of the site-scale model in GEMS is based on the spatial and temporal joint frequency distribution (JFD) of major variables (e.g., time-series LULC changes, climate, soil texture and antecedent SOC content, management, 
and other disturbances). A more detailed description of the model system can be found in Liu [11] and Liu et al. [9].

2.2.2. Uncertainty Control of Ensemble Simulations. GEMS simulations of each JFD case (i.e., the simulation unit whose size is $60 \mathrm{~m}$ by $60 \mathrm{~m}$ in this study and the total number of simulation units are 35,898 ) were executed to incorporate the variability of inputs. Values of selected output variables were written to a set of output files after each model execution and then aggregated for the study area using the SAS Macros program embedded in GEMS. The uncertainty of simulations was evaluated in terms of the coefficient of variation with all model outputs [11, 14]. The estimation of net primary productivity (NPP) was set up with a maximum potential NPP parameter for each LULC type by manually adjusting it to match the NPP estimate from the literature for forests, grasslands, wetlands, and shrublands, respectively. Grain yields of major crops (including corn, oats, soybeans, spring wheat, and sunflowers) from the USDA National Agricultural Statistics Service (NASS) (http://www.nass.usda.gov/Data_and_Statistics/Quick_Stats/ index.asp) and observed biomass productivity data from the literature were also used as references to validate corresponding outputs. Figure 2 indicates that about $81 \%$ of variance can be explained, ensuring our confidence in simulated results.

\subsection{Major Geospatial and Attribute Data}

2.3.1. Annual Land Use Imagery. In this study, the cropland maps (i.e., annual cropland data layers between 1998 and 2007) generated from $30 \mathrm{~m}$ Landsat Thematic Mapper (TM) imagery (1998 to 2005) and $56 \mathrm{~m}$ AWiFS (Advanced Wide Field Sensor) imagery (2006 and 2007) (http://www.nass.usda.gov/research/Cropland/SARSla.htm) were used to detect the annual change in LULC type. Due to the differences in imagery sources and the cropping system focus, these remotely sensed images were finalized with identical classification system and spatial resolution $(60 \mathrm{~m})$. The 2001 National Land Cover Database (NLCD) was geospatially referenced to define noncropland classes by ignoring their temporal change since 1998.

2.3.2. Climate Data. The climate variables used to drive model simulations included mean monthly minimum and maximum temperatures and mean monthly precipitation from 1970 to 2007. These data were derived from the PRISM climate database of the United States (http://www.prism.oregonstate.edu/products/). The annual precipitation and mean temperature from 1970 to 2007 are illustrated in Figure 3, which indicates substantial interannual fluctuations of both variables.

2.3.3. Cropping and Management Data. The dataset of crop composition and crop rotation probability was available at http://www.nrcs.usda.gov/technical/NRI/, and tillage and residue management statistics were provided by the Conservation Technology Information Center [17].

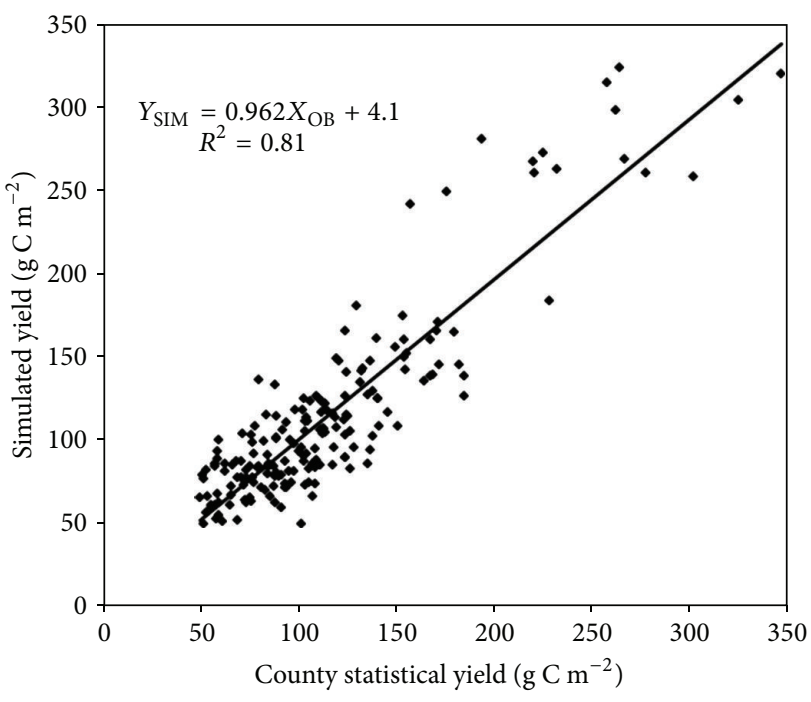

FIGURE 2: Comparison of simulated crop yields (of corn, oats, soybean, spring wheat, and sunflower) and USDA county statistical yields across the study area from 1972 to 2007.

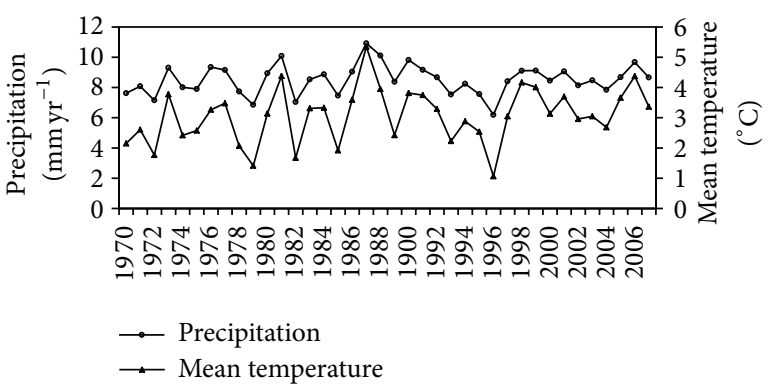

FIGURE 3: Annual precipitation and mean temperature over the study area from 1970 to 2007.

2.3.4. Soil Database and Baseline Soil Organic Carbon. The Soil Survey Geographic (SSURGO) Database (http://soils .usda.gov/survey/geography/ssurgo/) was used to initiate SOC simulations in the early 1970s. Soil attributes used in modeling included soil texture (sand, silt, and clay fractions), bulk density, soil organic matter content, wilting point, and field water capacity. Compound Topographic Indices (http://edna.usgs.gov/Edna/datalayers/cti.asp) were used to characterize soil drainage classes from the excessively well drained to the very poorly drained as defined by Soil Survey Division Staff [18].

Using the SSURGO database coupled with the historical climate records dating back to 1970, no change in land use was assumed prior to 1998 (no such data available) for GEMSEDCM to simulate the historical SOC trend in the top $20 \mathrm{~cm}$ depth of soil prior to 1998, and the SOC contents as of 1998 were taken as the baseline for model simulations for the period from 1998 to 2007.

2.4. Analyses of Simulation Outputs. All model outputs (e.g., grain yield, NPP, and SOC content) from 35,898 simulation units were aggregated with area weight for each LULC type. 

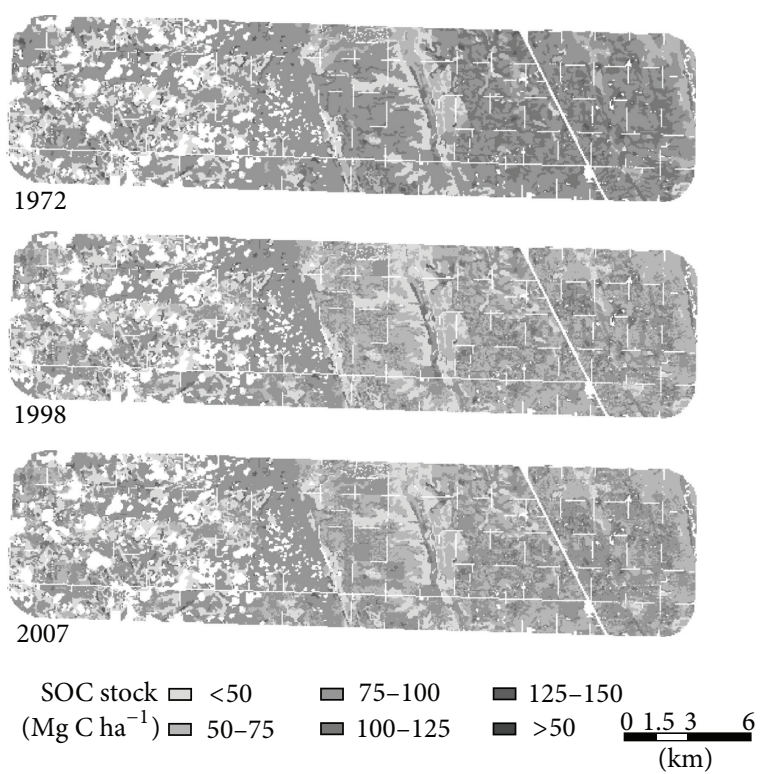

FIgURE 4: The spatial distribution of the SOC stock magnitudes across the study area in 1972, 1998, and 2007.

Previous studies $[5,6]$ suggested that the rate of SOC change induced by land surface disturbances is related to the baseline SOC magnitude in the northwestern Great Plains. And this relation can be used to predict the mean change in SOC from the mean baseline value despite a possible exaggeration of the spatial variability in the mean rate of SOC change due to the spatial variations in baseline values [4]. Therefore, we used an interval of $10 \mathrm{Mg} \mathrm{ha}^{-1}$ to group the baseline SOC levels in 1972 derived from the SSURGO soil database and in 1998 from model simulations and then defined the annual rate of SOC change within each LULC type for the periods from 1972 to 1998 and from 1998 to 2007 , respectively.

\section{Results and Discussion}

3.1. Historical SOC Change Trends. The data presented in Table 2 indicate that the average SOC stock in the top $20 \mathrm{~cm}$ depth of soil over the study area declined from 85.8 $\mathrm{MgCha}^{-1}$ in 1972 to $75.9 \mathrm{MgCha}^{-1}$ in 1998 at a loss rate of $0.38 \mathrm{MgC} \mathrm{ha}^{-1} \mathrm{yr}^{-1}$, varying from $0.45 \mathrm{MgCha}^{-1} \mathrm{yr}^{-1}$ in cropland to $0.11 \mathrm{MgCha}^{-1} \mathrm{yr}^{-1}$ in grassland. Since 1998, the study area had become a SOC sink at an annual rate of $44 \mathrm{~kg} \mathrm{Cha}^{-1} \mathrm{yr}^{-1}$. The spatial patterns of the SOC stock change from the baseline as of 1998 and 2007 are illustrated in Figure 4. In fact, prior to the 1990s, the conversions of grasslands and wetlands to cropping systems coupled with a predominant conventional tillage (CT) had enhanced SOC depletion. As addressed above, the changes in land use and tillage practices as driving forces were integrated into our simulations. Therefore, a reduction in SOC loss rate since then could be attributed mainly to an increase in conservation tillage management (e.g., both no-till and reduced tillage increased from 6\% in 1989 to $57 \%$ in 2004) and an expansion of corn-planted areas (Table 1) (corn usually has a higher

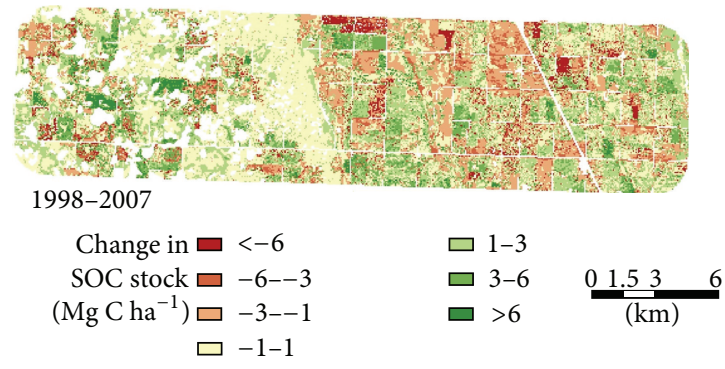

FIgURE 5: Spatially explicit sinks and sources of SOC in the top $20 \mathrm{~cm}$ depth of soil as of 2007 in comparison with the baseline in 1998. Red color represents sources and green color represents sinks.

biomass yield and results in more residue in the field than other crops), together leading to a neutral/small SOC sink over the affected areas (see Figure 5).

3.2. Annual SOC Change Rate as Related to the Baseline SOC Stocks. The data presented in Table 2 also indicate that the annual change rate of SOC stock not only varied with LULC type but also with time period. The relations of the annual SOC change rate against the baseline SOC level are illustrated in Figure 6. The annual change rate was more logarithmically functional of the baseline SOC magnitude than linearly. On the average, the regression model could explain about $84 \%$ of all variance where the coefficient of determination $\left(R^{2}\right)$ ranged from 0.88 for cropland to 0.89 for grassland (see Figure 6(a)). As mentioned previously, prior to the 1990s, the study area experienced an expansion of croplands from grasslands and wetlands. This expasion had led to a great reduction in SOC stock due to CT-enhanced decomposition of soil organic matter. An extension of conservation tillage since the beginning of the 1990s and an increase in cornplanted area since the end of the 1990s had also significantly mitigated the rate of SOC loss and made the area turn into a small C sink from a big C source.

Previous studies suggested that soils with higher C contents tended to lose more $\mathrm{C}$ following land surface disturbances [5, 6, 9] and climate warming [4]. In other words, the loss rate becomes smaller with a decrease in the antecedent SOC level. Figure 6(b) illustrates that the magnitude and direction of the annual SOC change depends heavily on the level of baseline SOC stock. The average change rate during the period from 1972 to 2007 was about $-0.19 \pm$ $0.38 \mathrm{MgCha}^{-1} \mathrm{yr}^{-1}$. Generally, soils with higher baseline SOC contents (e.g., average greater than about $50 \mathrm{MgCha}^{-1}$ within the top $20 \mathrm{~cm}$ soil layer in this study) tend to lose soil $\mathrm{C}$ and do so even under conservation practices, while soils having lower $\mathrm{C}$ contents (saying lower than $40 \mathrm{MgC} \mathrm{ha}^{-1}$ in this study) likely sequester $\mathrm{C}$ from the atmosphere under conservation management. However, the $\mathrm{C}$ sequestration capacity of a soil is also dependent upon soil type and other conditions such as drainage class cropping system [5]. As illustrated in Figure 6(b), the change rate did not vary much with the time period despite the difference in the intercept 
TABLE 2: The baseline SOC stocks of major land use classes and their change rates.

\begin{tabular}{|c|c|c|c|c|c|c|c|c|}
\hline \multirow{2}{*}{ Land use type } & \multicolumn{3}{|c|}{ Number of pixel $^{\mathrm{a}}$} & \multirow{2}{*}{$\begin{array}{c}\text { Change in pixel } \\
1998-2007\end{array}$} & \multirow{2}{*}{$\begin{array}{c}\text { SOC in } 1972 \\
\mathrm{Mg} \mathrm{C} / \mathrm{ha}\end{array}$} & \multirow{2}{*}{$\begin{array}{l}1972-1998^{\mathrm{b}} \\
\mathrm{Mg} \text { C/ha/yr }\end{array}$} & \multirow{2}{*}{$\begin{array}{c}\text { SOC in } 1998 \\
\mathrm{Mg} \text { C/ha }\end{array}$} & \multirow{2}{*}{$\begin{array}{c}\text { 1998-2007 } \\
\mathrm{Mg} \mathrm{C} / \mathrm{ha} / \mathrm{yr}\end{array}$} \\
\hline & 1972 & 1998 & 2007 & & & & & \\
\hline Forest & 275 & 237 & 297 & 60 & 74.0 & -0.22 & 75.0 & -0.02 \\
\hline Grassland & 7344 & 6618 & 4865 & -1753 & 81.9 & -0.11 & 76.1 & 0.04 \\
\hline Agriculture & 26327 & 24342 & 22705 & -1637 & 86.6 & -0.45 & 75.9 & 0.05 \\
\hline Wetland & 1836 & 1684 & 3309 & 1625 & 95.9 & -0.38 & 75.6 & 0.04 \\
\hline Mean & & & & & 85.8 & -0.38 & 75.9 & 0.04 \\
\hline Stdev & & & & & 22.9 & 0.27 & 19.7 & 0.40 \\
\hline
\end{tabular}

Pixel size $=60 \times 60 \mathrm{~m}^{2}$.

${ }^{\mathrm{b}}$ Baseline SOC stocks in 1998 for each land use type are not necessarily associated with the calculation of annual SOC change rate for 1972-1998 because of land use change.

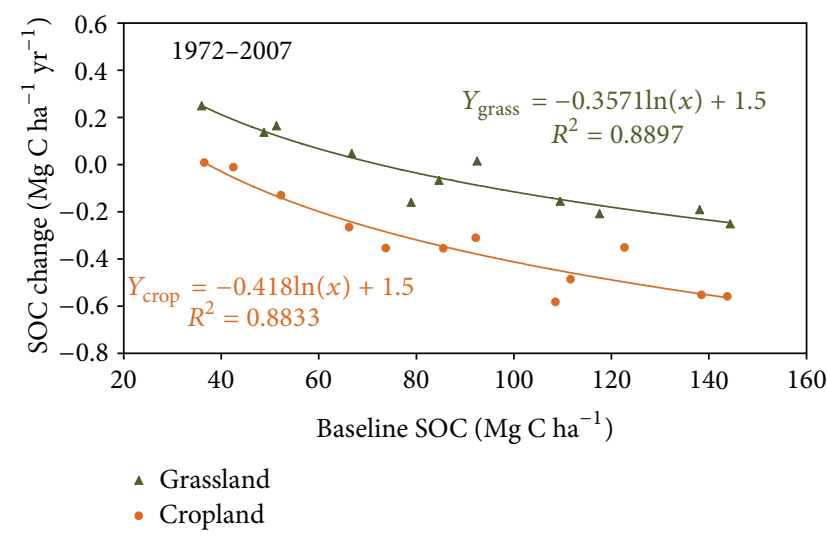

(a)

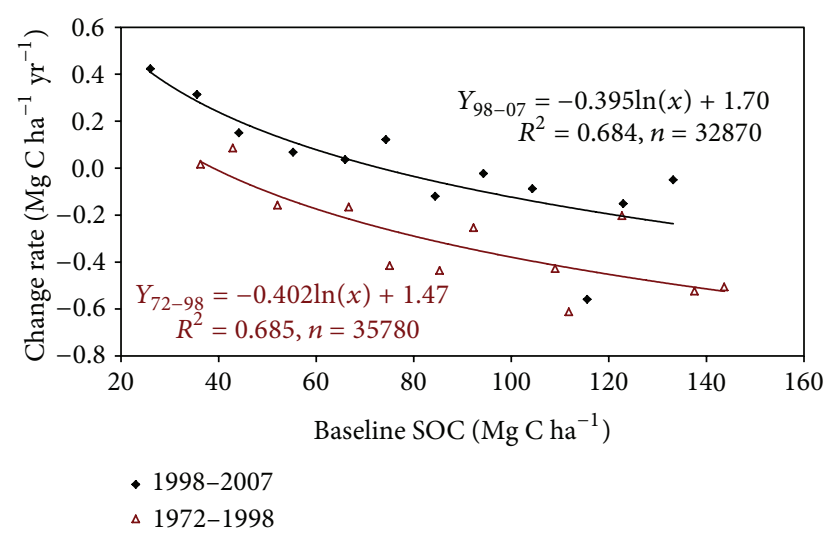

(b)

FIGURE 6: Annual rate of the change in soil organic carbon stock (SOC) in the top $20 \mathrm{~cm}$ depth of soil as related to the baseline SOC levels across the study area. (a) Annual rate of SOC change from 1972 to 2007 for cropland and grassland; (b) annual rate of SOC change averaged for all land use types from 1972 to 1998 and 1998 to 2007.

value due to the difference in the baseline magnitude at its initial year of 1972 and 1998, respectively.

The relationship between the change rate and the baseline SOC content has been reported for other regions $[3,5,6,9]$. By modeling to evaluate historical SOC trends dynamics for the northwest Great Plains of the United States, Tan et al. [6] concluded that SOC losses from cultivated croplands are unavoidable, regardless of tillage methods, and a reduction of SOC loss rate depends mainly upon the antecedent SOC levels and tillage methods. This conclusion is similar to that made by Tan et al. [5], which was based on the meta-analysis and empirical modeling of the northeastern central USA (including the East Corn Belt). This study observed a critical role of tillage practices in the SOC dynamics of croplands. The conversion from conventional tillage to no-till could reduce SOC emissions by $16.8 \%$. Additionally, Bellamy et al. [3] reported that the annual loss rate of SOC from soils across England and Wales over the survey period between 1978 and 2003 ranged from $0.6 \%$ to $2.0 \%$ and found that the SOC loss rate accelerated linearly with the antecedent SOC content levels. They also believed that both the decrease in SOC stock over the time and its relationship to the baseline SOC level were attributed to climate change and did little with land use types. In fact, the losses of SOC observed in England and Wales could not be attributed to climate change only [7]. Our results showed that the SOC change rate varied temporally in cropland, which matched the history of conservation tillage implementation. Using Century to model SOC dynamics in cropland, improved pasture, and native pasture lands in Australia, Hill [19] documented the large influence of starting SOC levels within management types on simulation outputs, which is generally in response to changes in climate and management practices. He also noticed that the soils with higher initial SOC contents tend to lose more soil C even though the change percentage (over the initial SOC level) is smaller than that for the soils having lower initial SOC contents. A similar conclusion has recently been addressed by Lin and Zhang [20] for corn and soybean rotation system and grasslands in the northwestern Great Plains of the United States.

3.3. Effects of Land Use and Climate. The effects of climatic variables on annual SOC change were not only related to the interannual fluctuations of both precipitation and temperature, but also varied with LULC types (see Figures 3 and 7). 


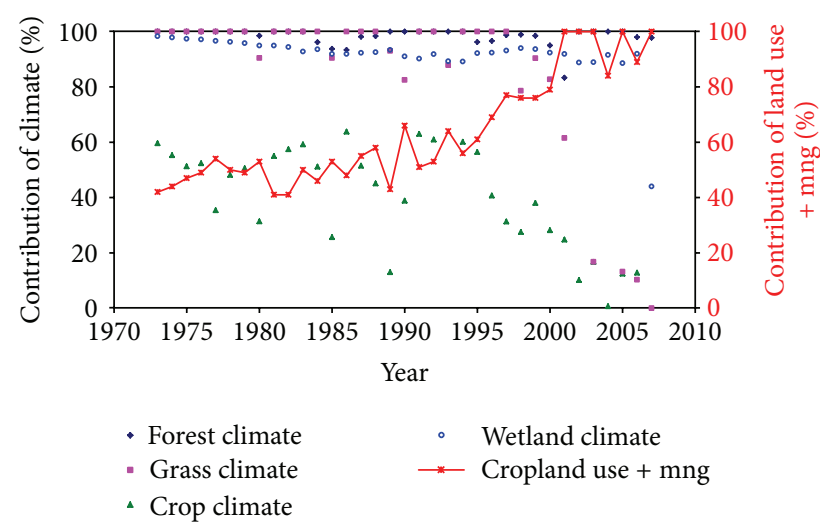

FIGURE 7: The contribution of climate variation and changes in land use (crop rotation in this case) and management practices to the annual SOC change (i.e., the difference in SOC stock from that in the previous year).

For lesser human-disturbed ecosystems such as forestlands and wetlands in this study, the annual change in SOC stock from the previous year could be almost totally attributed to the climate variations (98\% for forestland and $92 \%$ for wetlands), while the contribution of climatic variables was $78 \%$ for grasslands and only $37 \%$ for cropping systems. More interestingly, the impact of climate variation on cropping systems declined from about $60 \%$ in the early 1970 s to almost nothing in 2007, which appeared to be totally offset by the combined effects of both crop rotation and land management practices. Bell and Worrall [21] noted that, besides the role of baseline SOC level, the differences in land management practices could be more responsible for the variation in SOC stock than either soil taxonomic class or LULC type. The crop residue management survey data provided by the Conservation Technology Information Center [17] indicate that, from 1989 to 2004, the acreage with CT declined from $90 \%$ to about $20 \%$; meanwhile, the area with conservation tillage increased from $6 \%$ to $57 \%$. Particularly, the corn-planted area increased from $0.5 \%$ in 1998 to $13.6 \%$ in 2007, which was also coupled with a significant increase in soybeans (see Table 1). A rapid increase in the biomass inputs (residue and roots) of corn (from 2.36 Mg ha ${ }^{-1}$ in 1991 to $10.66 \mathrm{Mg} \mathrm{ha}^{-1}$ in 2010 , calculated from USDA NASS Statistics) to soil resulted from increased planted area and biomass yield over time, along with increased conservation tillage and corn rotation, could significantly reduce SOC loss rate from fertile Prairie Pothole soils or enhance $\mathrm{C}$ sequestration $[9,22]$. This finding could be the reason why, since 1996, the annual SOC change rate of croplands had dominantly been influenced by land use and management practices.

\section{Conclusions}

Based on simple kinetic considerations, the factors addressed above can drive the intrinsic rate of organic $\mathrm{C}$ decomposition in soil; therefore, a greater rate of SOC loss from the soil with a higher SOC content would be expected. However, the spatial variability could be exaggerated by the differences in baseline SOC magnitudes. Our conclusions based on this study are:

(1) Annual change in cropping systems was a major force driving spatial variability of annual SOC budgets across all croplands.

(2) The remarkable increment in biomass production following an increase in corn-planted area along with an extension of conservation tillage practices significantly mitigated soil $\mathrm{C}$ emissions and altered the cropping systems from a large $\mathrm{C}$ source to a small C sink.

(3) Annual change rate of SOC stocks in all land use and land cover types depended mainly on the baseline SOC levels, and soils with higher baseline SOC contents tend to be $\mathrm{C}$ sources; otherwise, they are likely to turn into $\mathrm{C}$ sinks following conservation management practices.

\section{Acknowledgments}

The authors thank Zhengpeng Li for assisting with model simulations, Sandra Poppenga and Bruce Worstell for providing the CTI data, and Md Shahriar Pervez for providing the irrigation map. The work of $\mathrm{Z}$. Tan was performed under USGS Contract no. G08PC91508.

\section{References}

[1] W. M. Post and K. C. Kwon, "Soil carbon sequestration and land-use change: processes and potential," Global Change Biology, vol. 6, no. 3, pp. 317-327, 2000.

[2] S. Del Grosso, D. Ojima, W. Parton, A. Mosier, G. Peterson, and D. Schimel, "Simulated effects of dryland cropping intensification on soil organic matter and greenhouse gas exchanges using the DAYCENT ecosystem model," Environmental Pollution, vol. 116, supplement 1, pp. S75-S83, 2002.

[3] P. H. Bellamy, P. J. Loveland, R. I. Bradley, R. M. Lark, and G. J. D. Kirk, "Carbon losses from all soils across England and Wales 1978-2003," Nature, vol. 437, no. 7056, pp. 245-248, 2005.

[4] R. M. Lark, P. H. Bellamy, and G. J. D. Kirk, "Baseline values and change in the soil, and implications for monitoring," European Journal of Soil Science, vol. 57, no. 6, pp. 916-921, 2006.

[5] Z. Tan, R. Lal, and S. Liu, "Using experimental and geospatial data to estimate regional carbon sequestration potential under no-till management," Soil Science, vol. 171, no. 12, pp. 950-959, 2006.

[6] Z. Tan, S. Liu, C. A. Johnston, J. Liu, and L. L. Tieszen, "Analysis of ecosystem controls on soil carbon source-sink relationships in the northwest Great Plains," Global Biogeochemical Cycles, vol. 20, no. 4, Article ID GB4012, 2006.

[7] P. Smith, S. J. Chapman, W. A. Scott et al., "Climate change cannot be entirely responsible for soil carbon loss observed in England and Wales, 1978-2003," Global Change Biology, vol. 13, no. 12, pp. 2605-2609, 2007.

[8] Z. Tan, L. L. Tieszen, S. Liu, and E. Tachie-Obeng, "Modeling to evaluate the response of savanna-derived cropland to warmingdrying stress and nitrogen fertilizers," Climatic Change, vol. 100, no. 3-4, pp. 703-715, 2010. 
[9] S. Liu, Z. Tan, Z. Li, S. Zhao, and W. Yuan, "Are soils of Iowa USA currently a carbon sink or source? Simulated changes in SOC stock from 1972 to 2007," Agriculture, Ecosystems and Environment, vol. 140, no. 1-2, pp. 106-112, 2011.

[10] Z. Tan, S. Liu, N. Bliss, and L. L. Tieszen, "Current and potential sustainable corn stover feedstock for biofuel production in the United States," Biomass and Bioenergy, vol. 47, pp. 372-386, 2012.

[11] S. Liu, "Quantifying the spatial details of carbon sequestration potential and performance," in Carbon Sequestration and Its Role in the Global Carbon Cycle, B. McPherson and E. Sundquist, Eds., pp. 117-128, American Geophysical Union, Washington, DC, USA, 2009.

[12] S. Q. Zhao, S. Liu, Z. Li, and T. L. Sohl, "Ignoring detailed fast-changing dynamics of land use overestimates regional terrestrial carbon sequestration," Biogeosciences, vol. 6, no. 8, pp. 1647-1654, 2009.

[13] R. A. Gleason, M. K. Laubhan, and N. H. Euliss, Ecosystem Services Derived from Wetland Conservation Practices in the United States Prairie Pothole Region With an Emphasis on the U.S. Department of Agriculture Conservation Reserve and Wetlands Reserve Programs, Professional Paper 1745, U.S. Geological Survey, Reston, Va, USA, 2008.

[14] S. Liu, T. R. Loveland, and R. M. Kurtz, "Contemporary carbon dynamics in terrestrial ecosystems in the Southeastern Plains of the United States," Environmental Management, vol. 33, supplement 1, pp. S442-S456, 2004.

[15] W. J. Parton, D. S. Schimel, C. V. Cole, and D. S. Ojima, "Analysis of factors controlling soil organic matter levels in Great Plains grasslands," Soil Science Society of America Journal, vol. 51, no. 5, pp. 1173-1179, 1987.

[16] S. Liu, N. Bliss, E. Sundquist, and T. G. Huntington, "Modeling carbon dynamics in vegetation and soil under the impact of soil erosion and deposition," Global Biogeochemical Cycles, vol. 17, no. 2, 2003.

[17] Conservation Technology Information Center, National Crop Residue Management Survey Data (CD-ROM), Conservation Technology Information Center, West Lafayette, Ind, USA, 2008.

[18] Soil Survey Division Staff, Soil Survey Manual, vol. 18 of Handbook, U.S. Department of Agriculture, Soil Conservation Service, Washington, DC, USA, 1993.

[19] M. J. Hill, "Generating generic response signals for scenario calculation of management effects on carbon sequestration in agriculture: approximation of main effects using CENTURY," Environmental Modelling and Software, vol. 18, no. 10, pp. 899913, 2003.

[20] Z. Lin and R. Zhang, "Effects of climate change and elevated atmospheric $\mathrm{CO}_{2}$ on soil organic carbon: a response equation," Climatic Change, vol. 113, no. 2, pp. 107-120, 2012.

[21] M. J. Bell and F. Worrall, "Estimating a region's soil organic carbon baseline: the undervalued role of land-management," Geoderma, vol. 152, no. 1-2, pp. 74-84, 2009.

[22] T. O. West and W. M. Post, "Soil organic carbon sequestration rates by tillage and crop rotation: a global data analysis," Soil Science Society of America Journal, vol. 66, no. 6, pp. 1930-1946, 2002. 

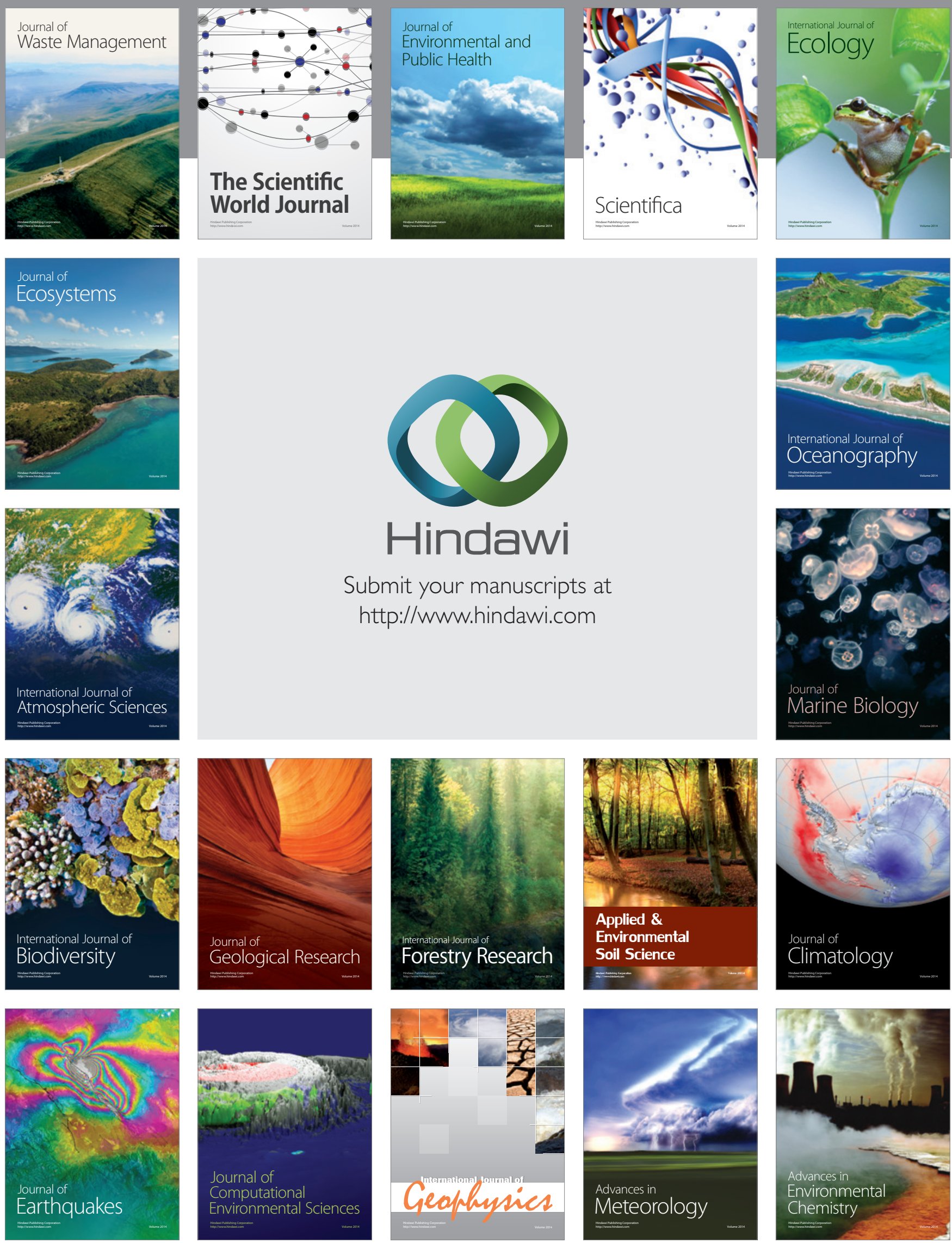